\title{
Physical activity in established rheumatoid arthritis and variables associated with maintenance of physical activity over a seven-year period - a longitudinal observational study
}

\author{
Ann Bremander $1,2,3,4^{*}$ (D) Karina Malm ${ }^{4,5}$, Maria L. Andersson ${ }^{1,4}$ and on behalf of the BARFOT study group
}

\begin{abstract}
Background: A large number of patients with RA do not adhere to the recommended levels of physical activity to enhance health. According to EULAR recommendations, physical activity should be part of standard care in people with rheumatic diseases. There have been few larger studies on maintenance of physical activity over longer periods of time. The aim was to study self-reported physical activity levels over 7 years in patients with established rheumatoid arthritis (RA). In addition, to determine variables associated with maintenance or change of physical activity behavior.
\end{abstract}

Methods: Questionnaires were sent to the BARFOT cohort in $2010(n=1525)$ and in $2017(n=1046)$, and 950 patients responded to both questionnaires. Patients were dichotomized according to meeting MVPA recommendations (physically active at a moderate level $\geq 150 \mathrm{~min} /$ week or at an intense level $\geq 75 \mathrm{~min} /$ week) or not. Body mass index, smoking habits, tender joint count (TJC), swollen joint count (SJC), Patient Global Assessment (PatGA), pain intensity and distribution, fatigue, physical function (HAQ), health-related quality of life (EQ. 5D), comorbidities, and medical treatment were assessed. We used logistic regression analysis to study variables associated with maintenance and/or change of MVPA behavior.

Results: Forty-one per cent $(n=389)$ of the patients met MVPA recommendations on both occasions. Patients who met MVPA recommendations over 7 years were younger and a higher proportion were never-smokers. There was a negative association with being overweight or obese, having cardiovascular or pulmonary diseases, pain, fatigue, and physical function, whereas there was a positive association between QoL and maintaining MVPA recommendations. Similar factors were positively associated with a deterioration in physical activity level over time. (Continued on next page)

\footnotetext{
* Correspondence: ann.bremander@fou-spenshult.se

'Department of Clinical Sciences, Rheumatology, Faculty of Medicine, Lund University, Lund, Sweden

${ }^{2}$ Department of Regional Health Research, University of Southern Denmark, Odense, Denmark

Full list of author information is available at the end of the article
}

(c) The Author(s). 2020 Open Access This article is licensed under a Creative Commons Attribution 4.0 International License, which permits use, sharing, adaptation, distribution and reproduction in any medium or format, as long as you give appropriate credit to the original author(s) and the source, provide a link to the Creative Commons licence, and indicate if changes were made. The images or other third party material in this article are included in the article's Creative Commons licence, unless indicated otherwise in a credit line to the material. If material is not included in the article's Creative Commons licence and your intended use is not permitted by statutory regulation or exceeds the permitted use, you will need to obtain permission directly from the copyright holder. To view a copy of this licence, visit http://creativecommons.org/licenses/by/4.0/. The Creative Commons Public Domain Dedication waiver (http://creativecommons.org/publicdomain/zero/1.0/) applies to the data made available in this article, unless otherwise stated in a credit line to the data. 
(Continued from previous page)

Conclusions: Maintenance of physical activity over a long period of time is challenging for patients with established RA. Reports of high quality of life supported maintenance of physical activity while disease related and unhealthy lifestyle factors had a negative effect. Health professionals should consider the patient's standpoint when encouraging maintenance of physical activity, preferably using coordinated lifestyle interventions.

Keywords: Rheumatoid arthritis, Physical activity, Exercise, Longitudinal study

\section{Background}

Promoting a healthy lifestyle has been popular in the past decade, not only in the general population $[1,2]$ but also for people with chronic inflammatory diseases. Interventions to support changes in lifestyle such as healthy eating and drinking, smoking cessation, and increasing the amount of weekly physical activity and exercise have been recommended in a number of guidelines to promote health in the rheumatoid arthritis (RA) population [3, 4]. Patients with RA have a higher risk of developing cardiovascular diseases and metabolic syndrome, among other comorbidities [5, 6]. Physical activity reduces the risk of these comorbidities in the general population [7], and there is some evidence that it might also be an effective treatment for patients with RA $[8,9]$. It is well known that a large number of patients with RA have a sedentary lifestyle and are less active than their healthy counterparts [10]. Large population-based studies have found a prevalence of health-enhancing physical activity ranging from 20 to $70 \%$ in people with chronic inflammatory arthritis [11-13], depending on the methodology used and the country investigated.

Recommendations concerning health-enhancing physical activity require moderate physical activity (MPA) for $\geq 150 \mathrm{~min} /$ week or PA at a vigorous level for $\geq 75 \mathrm{~min} /$ week (VPA) [14, 15]. These recommendations also apply to people with rheumatic diseases [9]. Being physically active, defined as meeting moderate-to-vigorous physical activity (MVPA) recommendations, has the possibility of reducing disease burden in RA and may contribute to an improved quality of life (QoL) [12]. Factors that negatively affect the possibility of being physically active according to the recommendations are higher disease activity, worse pain and function, lower mental health, older age, worse health status, lower education, lower self-efficacy, and lack of social support [16-18]. While the prevalence of meeting physical activity recommendations has been well studied, there have been few larger studies on maintenance over longer periods of time $[16,18]$. Maintaining a physically active lifestyle will affect overall health and may improve the impact of some common comorbidities in the RA population. A better understanding of variables associated with maintenance, improvement or deterioration in physical activity levels over time can help health care professionals to coach patients with RA in behavior change.
The aim of the present study was to investigate selfreported physical activity levels over 7 years in a welldefined RA cohort, and to determine variables associated with maintenance or change of physical activity behavior.

\section{Methods \\ Patients}

This study involved patients with RA from the BARFOT (Better Anti-Rheumatic PharmacOTherapy) cohort, who were recruited between 1992 and 2006 and included in the study at the time for diagnosis $(n=2837)$. All patients fulfilled the American College of Rheumatology (ACR) criteria for classification of RA [19] and had a disease duration of $\leq 12$ months. The patients were treated with DMARDs in accordance with the recommended treatment strategy in Sweden, as described in earlier studies [20]. The patients were assessed according to a structured protocol at inclusion and after 3, 6, 12, 24, 60, 96, and 180 months. In 2010 and in 2017, a lifestyle questionnaire was sent to the patients. There were response rates of $73 \%(n=1525)$ and $68 \%(n=1046)$ respectively, and 950 patients responded to both questionnaires. These patients made up our study cohort.

\section{Lifestyle questionnaire}

In this study, well-used and validated outcome measures hypothesized to be of importance for patient-reported physical activity were assessed: disease characteristics, measures of health-related quality of life, physical functioning, fatigue, intensity and distribution of pain, and additional lifestyle information such as smoking and body mass index (BMI). The data were self-reported and retrieved from the 2010 questionnaire.

Disease characteristics assessed were self-reported tender joint count (TJC) and swollen joint count (SJC, 28 joints) [21], medical treatment, and comorbidity. Healthrelated quality of life was measured with the Euroqol 5 Dimensions (EQ-5D; 0-1, worst to best) [22] and patient global assessment (PatGA; numeric rating scale (NRS) 0-10, best to worst) [21]. Physical functioning was assessed with the Health Assessment Questionnaire (HAQ; 0-3, best to worst) [23]. Fatigue (NRS 0-10, best to worst), pain intensity (NRS $0-10$, best to worst), and 
pain distribution (pain mannequin, with 18 defined body regions) were assessed [24].

Physical activity was assessed with questions concerning frequency and duration, reported as minutes/week spent on moderate physically activity and on vigorous physical activity. The same two questions were posed in 2010 and in 2017, and adhered to Swedish population studies on lifestyle habits (only available in Swedish, https://www.socialstyrelsen.se/globalassets/sharepointdokument/dokument-webb/nationella-riktlinjer/levnadsvanor-fragor-om-levnadsvanor.pdf). To assess maintenance and change of physical activity levels, data from the questionnaires were dichotomized as either being active at recommended levels of physical activity for enhancement of health (MVPA: physically active at a moderate level $\geq 150 \mathrm{~min} /$ week (MPA) or at a vigorous level $\geq 75$ min/week (VPA)) or not (non-MVPA) [25].

\section{Statistics}

To test differences between groups, the chi-square test was used for proportions and Student's independent ttest was used for continuous variables, and all tests for significance were 2-tailed. The study sample was dichotomized as either achieving recommended levels of physical activity (MVPA) in 2010 and/or in 2017 or not (dependent variable). Three analyses were performed, (i) patients who met MVPA recommendations at both time points vs. participants who did not meet MVPA in 2010 or in 2017, (ii) patients who met MVPA recommendations at both time points vs. participants who reported a deterioration in physical activity level between 2010 and 2017, and (iii) patients who reported an improvement in physical activity level between 2010 and 2017 vs. patients who did not meet MVPA recommendations at any time point.

In this longitudinal study, we focused on variables from the 2010 questionnaire that were associated with the outcome 7 years later. Logistic regression analyses were used. All variables were adjusted for age, gender, and smoking habits. Statistical analyses were performed using SPSS Statistics 21 software (IBM Corp., Armonk, NY, USA).

\section{Results}

Altogether, 950 patients responded to both questionnaires; mean age was 61 (SD 13) years with a mean disease duration of 9 (SD 4) years in 2010, and 72\% were women (Table 1). The patients who were lost to followup were at inclusion in the BARFOT cohort, older (mean age 58 (SD 16) years vs. 52 (SD 13) years; $p<$ 0.001 ), had a worse DAS28 (mean 5.34 (SD 1.23) vs. 5.12 (SD 1.24); $p<0.001$ ), and a worse HAQ (mean 1.02 (SD $0.63)$ vs. 0.96 (SD 0.59); $p=0.024$ ).

\section{Physical activity levels over seven years}

Forty-one per cent $(n=389)$ of the patients met MVPA recommendations on both occasions, $66 \%(n=623)$ in 2010 and 53\% $(n=505)$ in 2017 (Fig. 1). In 2010, 32\% reported that they were physically active at a moderate level and $11 \%$ at a vigorous level, and $23 \%$ fulfilled the criteria by a combination of vigorous and moderate levels of physical activity. The corresponding figures in 2017 were 27, 14, and 12\%. A higher proportion of patients who reported having a VPA level in $2010(n=$ 324) also met MVPA recommendations in 2017 (75\%), as compared to those who reported having a MPA level in $2010(n=299)$, where $49 \%$ met MVPA recommendations in 2017.

Of the 327 patients who did not meet MVPA in 2010, $35 \%(n=116)$ improved and met MVPA recommendations in 2017. Of those who met MVPA recommendations in 2010, 38\% $(n=234)$ deteriorated and did not meet the MVPA recommendations in 2017 (Fig. 1).

\section{Factors associated with health enhancing physical activity} Patients who met MVPA recommendations generally had better outcomes in all areas measured at both occasions compared to those who did not meet MVPA recommendations at any occasion. However, there were no significant differences between genders or in the proportions of patients with RF [Additional file 1].

There was a negative association between meeting MVPA recommendations at both occasions and information from the 2010 questionnaire: age, being a smoker, being or obese, the presence of cardiovascular or pulmonary disease, TJC and SJC, PatGA, pain intensity, fatigue, physical function (HAQ), and pain distribution compared with patients who never met the MVPA recommendations. There was a positive association between meeting MVPA recommendations at both occasions and a better QoL in 2010 (EQ-5D), please see Table 2.

The same factors were associated with a deterioration in physical activity level over time. Patients who fulfilled MVPA recommendations in 2010 but not in 2017 were in 2010 older, more often overweight or obese, had more often cardiovascular and pulmonary comorbidities, reported more pain, worse fatigue and worse physical function and worse pain distribution compared with patients who maintained MVPA recommendations at both time points. There was an inversed relationship with QoL (Table 3).

There was a negative association between patients who improved in physical activity level over time and age, TJC, and pain distribution compared with those who did not meet MVPA recommendations at any occasion. An improvement was also associated with a better QoL (EQ. 5D) in 2010 (Table 4). Overweight or obesity were not 
Table 1 Descriptive of all patients who answered the questionnaire in 2010 and 2017

\begin{tabular}{|c|c|c|c|}
\hline & & $\begin{array}{l}\text { All patients in } 2010 \\
\text { Mean (SD) }\end{array}$ & $\begin{array}{l}\text { All patients in } 2017 \\
\text { Mean (SD) }\end{array}$ \\
\hline N & & 950 & 950 \\
\hline Age & & $61(13)$ & \\
\hline gender & Women, \% & 72 & \\
\hline \multirow[t]{3}{*}{ Smoking habits } & Non smoker, \% & 42 & 42 \\
\hline & Smoker, \% & 16 & 11 \\
\hline & Previous smoker, & 42 & 47 \\
\hline$R F, \%$ & & 66 & \\
\hline Disease duration, years & & $8.7(3.8)$ & \\
\hline BMl & & $25.9(4.2)$ & $25.9(4.8)$ \\
\hline \multirow[t]{4}{*}{ BMl } & $<18.5, \%$ & 1 & 1 \\
\hline & $18.5-24.9, \%$ & 44 & 45 \\
\hline & $25.0-29.9, \%$ & 41 & 38 \\
\hline & $\geq 30, \%$ & 14 & 15 \\
\hline Fulfilling MVPA, \% & & 66 & 53 \\
\hline TJC & & $5.4(6.3)$ & $5.1(6.4)$ \\
\hline SJC & & $3.5(5.1)$ & $2.9(4.8)$ \\
\hline PatGA NRS (0-10) & & $2.9(2.3)$ & $3.0(2.4)$ \\
\hline Pain NRS (0-10) & & $3.3(2.5)$ & $3.4(2.5)$ \\
\hline Fatigue NRS (0-10) & & $4.1(2.8)$ & $4.1(2.8)$ \\
\hline HAQ & & $0.52(0.55)$ & $0.60(0.62)$ \\
\hline EQ 5D & & $0.74(0.20)$ & $0.72(0.24)$ \\
\hline Tender regions & & $4.3(3.8)$ & $3.9(3.7)$ \\
\hline Cardiovascular disease, \% & & 41 & 50 \\
\hline Pulmonary disease, $\%$ & & 9 & 12 \\
\hline \multirow[t]{4}{*}{ DMARD } & No DMARD, \% & 17 & 24 \\
\hline & CDMARD $^{a}$ & 54 & 43 \\
\hline & bDMARDa & 26 & 27 \\
\hline & Only corticosteroids ${ }^{a}$ & 3 & 6 \\
\hline
\end{tabular}

${ }^{a}$ with and without corticosteroids

BMI Body mass index, TJC Tender joint count, SJC Swollen joint count, PatGA Patient Global Assessment, NRS Numeric rating scale, HAQ Health Assessment Questionnaire, EQ. 5D Euroqol 5 Dimensions, DMARDs Disease modifying anti-rheumatic drugs, CDMARDs Conventional DMARDs, CS Corticosteroids

statistically significant in the multivariate model, but patients who improved over the 7 years, had in 2010 a lower BMI (mean $25.8 \mathrm{~kg} / \mathrm{m}^{2}$ SD 4.4 vs. $27.4 \mathrm{~kg} / \mathrm{m}^{2}$ SD 4.6, $p=0.005$ ) compared with those who did not change.

\section{Discussion}

Using a study with a prospective, longitudinal design, we investigated physical activity levels over 7 years in a population-based cohort of patients with established RA. We found that only four out of every ten patients reported having health-enhancing levels of physical activity at both time points. Maintaining recommended levels of physical activity is a challenge to people with RA, and this study searched for characteristic differences between those who stayed active vs. those who did not. We also studied improvement and deterioration in physical activity levels to find important factors to address in the clinic to enhance a healthy lifestyle.

A proportion of the patients who were physically active at baseline maintained this also at follow-up. Patients who reported other unhealthy lifestyle factors such as smoking and overweight, or who reported having cardiovascular or pulmonary comorbidities and worse pain, fatigue, and function in 2010 were less likely to perform health-enhancing physical activity 7 years later. These findings are supported by the findings of earlier cross-sectional studies [12] and the few longitudinal studies published on this subject [16]. Similar factors were of importance when studying those who improved or deteriorated in physical activity level over 7 


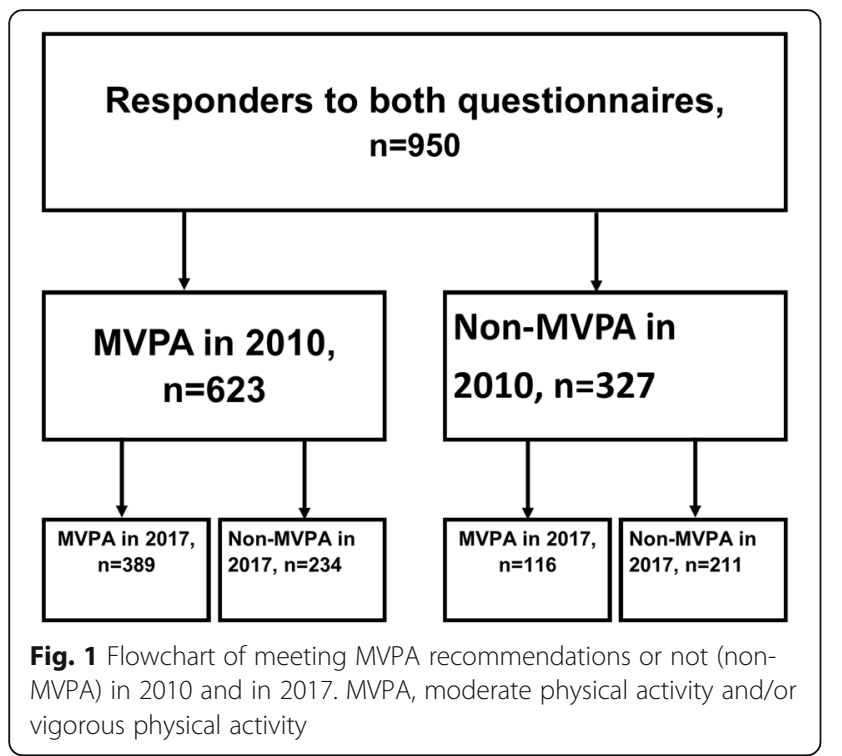

years. This indicates a need not only to design interventions for improvement of physical activity levels but also to screen for other lifestyle-related factors and design interventions addressing them as well as addressing high levels of pain and fatigue.

Only four out of every ten patients maintained healthenhancing physical activity over time, and one out of every ten patients improved in physical activity level, which may indicate that the healthcare sector has not been successful in screening and coaching a healthy lifestyle. Our patients had all met at least one physician, either in primary or in secondary care during the period investigated, and most likely other health professionals also. In Sweden, all health professionals are recommended to discuss lifestyle factors at healthcare visits in primary and in secondary care, and more studies on successful interventions are needed. In an earlier study on this cohort of patients, a large proportion of the subjects did not recall any discussions about lifestyle habits

Table 2 Variables (from 2010) associated with meeting MVPA recommendations on both occasions ( $n=389)$ vs. not meeting MVPA at any occasion ( $n=211$ ) (2010 and 2017). A logistic regression model adjusted for age, gender, and smoking habits

\begin{tabular}{|c|c|c|c|c|c|}
\hline 2010 & & $\mathrm{n}^{\mathrm{a}}$ & OR & $95 \% \mathrm{Cl}$ & $p$-value \\
\hline Age & & 594 & 0.979 & $0.969-0.989$ & $<0.001$ \\
\hline \multirow[t]{2}{*}{ Gender } & men & 164 & 1 & & \\
\hline & women & 430 & 1.176 & $0.801-1.726$ & 0.407 \\
\hline \multirow[t]{3}{*}{ Smoking habits } & Non smoker & 251 & 1 & & \\
\hline & Smoker & 92 & 0.591 & $0.357-0.980$ & 0.041 \\
\hline & Previous smoker & 251 & 0.743 & $0.507-1.089$ & 0.128 \\
\hline Disease duration, years & & 594 & 0.996 & $0.953-1.042$ & 0.875 \\
\hline \multirow[t]{4}{*}{ BMI } & $18.5-24.9, \%$ & 262 & 1 & & \\
\hline & $<18.5, \%$ & 4 & 1.050 & $0.102-10.758$ & 0.968 \\
\hline & $25.0-29.9, \%$ & 222 & 0.503 & $0.334-0.757$ & 0.001 \\
\hline & $\geq 30, \%$ & 81 & 0.242 & $0.141-0.414$ & $<0.001$ \\
\hline \multirow[t]{2}{*}{ Cardiovasc } & no & 361 & 1 & & \\
\hline & yes & 225 & 0.484 & $0.330-0.709$ & $<0.001$ \\
\hline \multirow[t]{2}{*}{ Pulmonary } & no & 545 & 1 & & \\
\hline & yes & 44 & 0.483 & $0.256-0.911$ & 0.025 \\
\hline TJC & & 587 & 0.960 & $0.934-0.987$ & 0.004 \\
\hline SJC & & 587 & 0.959 & $0.927-0.992$ & 0.015 \\
\hline PatGA (0-10) & & 583 & 0.883 & $0.819-0.952$ & 0.001 \\
\hline Pain (0-10) & & 581 & 0.908 & $0.846-0.974$ & 0.007 \\
\hline Fatigue $(0-10)$ & & 585 & 0.885 & $0.830-0.944$ & $<0.001$ \\
\hline HAQ (0-3) & & 589 & 0.476 & $0.344-0.658$ & $<0.001$ \\
\hline EQ 5D (0-1) & & 578 & 4.689 & $2.060-10.677$ & $<0.001$ \\
\hline Tender regions (0-18) & & 594 & 0.903 & $0.862-0.946$ & $<0.001$ \\
\hline \multirow[t]{4}{*}{ DMARD } & No DMARD & 107 & 1 & & \\
\hline & $\mathrm{CDMARD}^{\mathrm{b}}$ & 309 & 0.886 & $0.549-1.432$ & 0.622 \\
\hline & Biologic $^{\mathrm{b}}$ & 153 & 0.867 & $0.504-1.494$ & 0.608 \\
\hline & Only CS & 18 & 0.490 & $0.174-1.383$ & 0.178 \\
\hline
\end{tabular}

\footnotetext{
${ }^{a}$ included in the multivariate analyses, ${ }^{b}$ with and without corticosteroids
}

$B M I$ Body mass index, TJC Tender joint count, SJC Swollen joint count, PatGA Patient Global Assessment, NRS Numeric rating scale, HAQ Health Assessment Questionnaire, EQ. 5D Euroqol 5 Dimensions, DMARDs Disease modifying anti-rheumatic drugs, CDMARDs Conventional DMARDs, CS Corticosteroids 
Table 3 Variables (from 2010) associated with a deterioration in in physical activity level between 2010 and 2017 ( $n=234$ ) vs. meeting MVPA recommendations at both occasions $(n=389)$. A logistic regression model adjusted for age, gender, and smoking habits

\begin{tabular}{|c|c|c|c|c|c|}
\hline 2010 & & $\mathrm{n}^{\mathrm{a}}$ & OR & $95 \% \mathrm{Cl}$ & $p$-value \\
\hline Age & & 616 & 1.037 & $1.022-1.053$ & $<0.001$ \\
\hline \multirow[t]{2}{*}{ Gender } & men & 162 & 1 & & \\
\hline & women & 454 & 1.118 & $0.759-1.647$ & 0.572 \\
\hline \multirow[t]{3}{*}{ Smoking habits } & Non smoker & 264 & 1 & & \\
\hline & Smoker & 93 & 1.572 & $0.956-2.587$ & 0.075 \\
\hline & Previous smoker & 259 & 1.263 & $0.873-1.826$ & 0.216 \\
\hline Disease duration, years & & 616 & 0.969 & $0.928-1.013$ & 0.164 \\
\hline \multirow[t]{4}{*}{ BMI } & $18.5-24.9, \%$ & 290 & 1 & & \\
\hline & $<18.5, \%$ & 7 & 2.361 & $0.502-11.097$ & 0.277 \\
\hline & $25.0-29.9, \%$ & 238 & 1.702 & $1.180-2.468$ & 0.005 \\
\hline & $\geq 30, \%$ & 69 & 2.015 & $1.161-3.500$ & 0.013 \\
\hline \multirow[t]{2}{*}{ Cardiovasc } & no & 375 & 1 & & \\
\hline & yes & 235 & 1.863 & $1.290-2.691$ & 0.001 \\
\hline \multirow[t]{2}{*}{ Pulmonary } & no & 565 & 1 & & \\
\hline & yes & 47 & 2.106 & $1.129-3.927$ & 0.019 \\
\hline TJC & & 610 & 1.033 & $1.006-1.061$ & 0.016 \\
\hline SJC & & 606 & 1.025 & $0.992-1.059$ & 0.138 \\
\hline PatGA (0-10) & & 611 & 1.076 & $0.997-1.160$ & 0.059 \\
\hline Pain $(0-10)$ & & 607 & 1.087 & $1.014-1.164$ & 0.018 \\
\hline Fatigue (0-10) & & 611 & 1.072 & $1.007-1.142$ & 0.030 \\
\hline HAQ (0-3) & & 611 & 1.630 & $1.167-2.278$ & 0.004 \\
\hline EQ 5D (0-1) & & 605 & 0.382 & $0.162-0.899$ & 0.028 \\
\hline Tender regions (0-18) & & 615 & 1.076 & $1.028-1.126$ & 0.002 \\
\hline \multirow[t]{4}{*}{ DMARD } & No DMARD & 103 & 1 & & \\
\hline & CDMARD $^{\mathrm{b}}$ & 335 & 1.572 & $0.960-2.574$ & 0.072 \\
\hline & Biologic $^{b}$ & 161 & 1.491 & $0.858-2.589$ & 0.156 \\
\hline & Only CS & 15 & 1.493 & $0.472-4.720$ & 0.495 \\
\hline
\end{tabular}

a included in the multivariate analyses, ${ }^{b}$ with and without corticosteroids

$B M I$ Body mass index, TJC Tender joint count, SJC Swollen joint count, PatGA Patient Global Assessment, NRS Numeric rating scale, HAQ Health Assessment Questionnaire, EQ. 5D Euroqol 5 Dimensions, DMARDs Disease modifying anti-rheumatic drugs, CDMARDs Conventional DMARDs, CS Corticosteroids

during their healthcare visits, and a good proportion were not interested in such discussions [26]. A coordinated intervention to support lifestyle changes needs to be implemented in the healthcare sector, and early interventions appear to be helpful [27]. Such an intervention should be designed in line with behavioral theories, including educational components and a longer follow-up period [28, 29]. Personalized medicine may be one of several ways to help people who are at risk of developing RA to adhere to a healthy lifestyle [30-32].

We found transitions between the physically inactive group and the group classified as meeting healthenhancing physical activity recommendations over the 7 years, in both directions. The use of a cut-off may have contributed to the transition, but it was evident that patients who were active at a vigorous level tended to stay active over the years while a greater proportion of those who reported being active at a moderate level were later categorized as being physically inactive. The importance of vigorous exercise, if feasible, also for patients with chronic inflammatory diseases has been highlighted due to its possible anti-inflammatory effect and positive effect on the cardiac system, reducing the risk of cardiovascular disease $[8,9]$. If engaged in vigorous exercise as compared to moderate physical activity, people with rheumatic diseases are more likely to maintain healthy levels of physical activity over time [33], which is supported by our findings. In all regression analyses, older age was associated with a worse outcome in physical activity behavior. These findings might indicate a need for 
Table 4 Variables (from 2010) associated with an improvement in physical activity level between 2010 and 2017 ( $n=211)$ vs. not meeting MVPA recommendations at any occasion $(n=116)$. A logistic regression model adjusted for age, gender, and smoking habits

\begin{tabular}{|c|c|c|c|c|c|}
\hline 2010 & & $n^{a}$ & OR & $95 \% \mathrm{Cl}$ & $p$-value \\
\hline Age & & 322 & 0.963 & $0.945-0.981$ & $<0.001$ \\
\hline \multirow[t]{2}{*}{ Gender } & men & 97 & 1 & & \\
\hline & women & 225 & 1.061 & $0.628-1.972$ & 0.826 \\
\hline \multirow[t]{3}{*}{ Smoking habits } & Non smoker & 125 & 1 & & \\
\hline & Smoker & 59 & 0.732 & $0.379-1.416$ & 0.355 \\
\hline & Previous smoker & 138 & 0.683 & $0.403-1.156$ & 0.155 \\
\hline Disease duration, years & & 322 & 0.991 & $0.931-1.054$ & 0.764 \\
\hline \multirow[t]{4}{*}{ BMI } & $18.5-24.9, \%$ & 105 & 1 & & \\
\hline & $<18.5, \%$ & 3 & 1.964 & $0.166-23.159$ & 0.592 \\
\hline & $25.0-29.9, \%$ & 130 & 0.829 & $0.427-1.458$ & 0,516 \\
\hline & $\geq 30, \%$ & 62 & 0.555 & $0.276-1.116$ & 0.099 \\
\hline \multirow[t]{2}{*}{ Cardiovasc } & no & 171 & 1 & & \\
\hline & yes & 144 & 0.623 & $0.371-1.048$ & 0.074 \\
\hline \multirow[t]{2}{*}{ Pulmonary } & no & 283 & 1 & & \\
\hline & yes & 34 & 1.111 & $0.523-2.357$ & 0.785 \\
\hline TJC & & 318 & 0.946 & $0.906-0.987$ & 0.011 \\
\hline SJC & & 314 & 0.956 & $0.908-1.006$ & 0.082 \\
\hline PatGA (0-10) & & 311 & 0.904 & $0.812-1.006$ & 0.065 \\
\hline Pain (0-10) & & 315 & 0.915 & $0.826-1.015$ & 0.094 \\
\hline Fatigue $(0-10)$ & & 317 & 0.929 & $0.852-1.012$ & 0.092 \\
\hline HAQ (0-3) & & 322 & 0.719 & $0.463-1.116$ & 0.141 \\
\hline EQ 5D (0-1) & & 310 & 3.773 & $1.059-13.441$ & 0.041 \\
\hline Tender regions (0-18) & & 322 & 0.926 & $0.867-0.988$ & 0.020 \\
\hline \multirow[t]{4}{*}{ DMARD } & No DMARD & 50 & 1 & & \\
\hline & $\mathrm{CDMARD}^{\mathrm{b}}$ & 166 & 1.180 & $0.583-2.387$ & 0.645 \\
\hline & Biologic ${ }^{b}$ & 85 & 1.401 & $0.650-3.021$ & 0.390 \\
\hline & Only CS & 13 & 1.263 & $0.326-4.897$ & 0.735 \\
\hline
\end{tabular}

${ }^{a}$ included in the multivariate analyses, ${ }^{b}$ with and without corticosteroids

$B M I$ Body mass index, TJC Tender joint count, SJC Swollen joint count, PatGA Patient Global Assessment, NRS Numeric rating scale, HAQ Health Assessment Questionnaire, EQ. 5D Euroqol 5 Dimensions, DMARDs Disease modifying anti-rheumatic drugs, CDMARDs Conventional DMARDs, CS Corticosteroids

better coaching and adjustment of feasible activities, as patients with RA grow older.

Only a third (35\%) of the patients who reported being physically inactive at baseline reported being physically active at a moderate level at follow-up, while 65\% remained sedentary. We lack information on possible interventions, but we know from earlier studies that those who reported that they were active at a healthenhancing level in 2017 were more likely to have discussed physical activity with health professionals during a healthcare visit [26]. This probably reflects an interest in adhering to a healthy lifestyle, but not necessarily a successful intervention.

Maintenance of healthy levels of physical activity over time is challenging for patients with an established disease. The patient is not always aware of the positive and harmless effects of moderate or vigorous physical activity [34, 35]. Many patients struggle to find a balance in life; to regain a more normal life and adhere to a healthy lifestyle may be of great value, but also have a negative effect on a person's quality of life [34].

The study was based on self-reported information, and the low correlation between self-reported data, aerobic capacity, and physical activity measured with accelerometers has been well established [36]. However, the findings agree with earlier self-reported levels of physical activity in this population $[12,16]$. We do know from earlier studies that a number of biopsychosocial factors may affect a person's participation in physical activity, factors that were not available in this analysis. A high 
degree of disease activity, poor mental health, and patient perceptions of disease are associated with a sedentary lifestyle [16]. Also, fear-avoidance belief [37], selfefficacy, social support, and outcome expectations related to physical activity are of importance for participation in physical activity [12]. Self-reported physical activity, and especially moderate levels of physical activity, may be affected by the season in which it is reported [38], so it may be relevant to mention that both questionnaires were sent out in February/March. Yet another limitation is the lack of information concerning physical activity level during the seven-year time span, changes we have not accounted for could have occurred. In addition, self-reports of swollen and tender joints might be considered a limitation, but earlier studies has shown that these measures can be trusted [39].

\section{Conclusions}

Only four out of every ten patients with established RA maintained the recommended levels of physical activity over a seven-year period. Few improved in physical activity level while a larger proportion deteriorated. Worse health was associated with not maintaining healthenhancing physical activity, and the predictive factors were similar to those associated with worse performance in cross-sectional studies. Other unhealthy lifestyle factors and comorbidities reported had an effect on maintenance of physical activity, which is why coordinated supportive lifestyle interventions based on behavioral theories should be implemented in rheumatology care.

\section{Supplementary information}

Supplementary information accompanies this paper at https://doi.org/10. 1186/s41927-020-00151-6.

Additional file 1. Cross-sectional description and comparison between patients fulfilling MVPA recommendations or not (non-MVPA) in 2010 and 2017.

\begin{abstract}
Abbreviations
ACR: American College of Rheumatology; BARFOT: Better Anti-Rheumatic PharmacOTherapy; BMI: Body Mass Index; DAS28: 28-joint Disease Activity Score; DMARD: Disease-Modifying Anti-Rheumatic Drug; EQ 5 D: Euroqol 5 Dimensions; HAQ: Health Assessment Questionnaire; MVPA: Moderate-toVigorous Physical Activity; NRS: Numerical Rating Scale; PatGA: Patient Global Assessment; RA: Rheumatoid arthritis; RF: Rheumatoid factor; SJC: Swollen Joint Count; TJC: Tender Joint Count; QoL: Quality of Life
\end{abstract}

\section{Acknowledgements}

We would like to thank the participants of this study for their contribution. We also thank all the members of the BARFOT study group.

\section{Authors' contributions}

All authors (AB, KM and MA) contributed equally to the study design. KM were responsible for data collection, MA analyzed the data, all the authors contributed to interpretation of data, AB wrote the manuscript, and all the authors critically revised the manuscript, and the authors read and approved the final manuscript.

\section{Funding}

This work was supported by grants from the Swedish Rheumatism Association and the Foundation for Assistance to Disabled People in Skåne Sweden. The sponsors had no role in study design, data collection, data analysis, data interpretation, or writing of the report. Open access funding provided by Lund University.

\section{Availability of data and materials}

The datasets used and/or analyzed during the current study are available from the corresponding author on reasonable request.

\section{Ethics approval and consent to participate}

The study was approved by the ethical review board in Lund (entry nos. 2009/670 and 2016/896). The study adhered to the tenets of the Declaration of Helsinki and all patients gave their written informed consent.

Consent for publication

Not applicable.

\section{Competing interests}

The authors declare that they have no competing interests.

\section{Author details}

'Department of Clinical Sciences, Rheumatology, Faculty of Medicine, Lund University, Lund, Sweden. ${ }^{2}$ Department of Regional Health Research, University of Southern Denmark, Odense, Denmark. ${ }^{3}$ Danish Hospital for Rheumatic Diseases, University Hospital of Southern Denmark, Sønderborg, Denmark. ${ }^{4}$ Research and Development Center, Spenshult, Halmstad, Sweden. ${ }^{5}$ Rheumatology, Capio Movement, Halmstad, Sweden.

Received: 3 April 2020 Accepted: 27 July 2020

Published online: 08 October 2020

\section{References}

1. Khaw KT, Wareham N, Bingham S, Welch A, Luben R, Day N. Combined impact of health behaviours and mortality in men and women: the EPICNorfolk prospective population study. PLoS Med. 2008;5(1):e12.

2. Myint PK, Smith RD, Luben RN, Surtees PG, Wainwright NW, Wareham NJ, et al. Lifestyle behaviours and quality-adjusted life years in middle and older age. Age Ageing. 2011;40(5):589-95.

3. Combe B, Landewe R, Daien Cl, Hua C, Aletaha D, Alvaro-Gracia JM, et al. 2016 update of the EULAR recommendations for the management of early arthritis. Ann Rheum Dis. 2017;76(6):948-59.

4. Daien $\mathrm{Cl}$, Hua C, Combe B, Landewe R. Non-pharmacological and pharmacological interventions in patients with early arthritis: a systematic literature review informing the 2016 update of EULAR recommendations for the management of early arthritis. RMD Open. 2017;3(1):e000404.

5. Avina-Zubieta JA, Choi HK, Sadatsafavi M, Etminan M, Esdaile JM, Lacaille D. Risk of cardiovascular mortality in patients with rheumatoid arthritis: a metaanalysis of observational studies. Arthritis Rheum. 2008;59(12):1690-7.

6. Hallajzadeh J, Safiri S, Mansournia MA, Khoramdad M, Izadi N, AlmasiHashiani A, et al. Metabolic syndrome and its components among rheumatoid arthritis patients: a comprehensive updated systematic review and meta-analysis. PLoS One. 2017;12(3):e0170361.

7. Kyu HH, Bachman VF, Alexander LT, Mumford JE, Afshin A, Estep K, et al. Physical activity and risk of breast cancer, colon cancer, diabetes, ischemic heart disease, and ischemic stroke events: systematic review and doseresponse meta-analysis for the global burden of disease study 2013. BMJ. 2016;354:i3857.

8. Veldhuijzen van Zanten J, Sandoo A, Metsios GS, Stavropoulos-Kalinoglou A, Ntoumanis N, Kitas GD. Comparison of the effects of exercise and anti-TNF treatment on cardiovascular health in rheumatoid arthritis: results from two controlled trials. Rheumatol Int. 2019;39(2):219-25.

9. Rausch Osthoff AK, Niedermann K, Braun J, Adams J, Brodin N, Dagfinrud H, et al. 2018 EULAR recommendations for physical activity in people with inflammatory arthritis and osteoarthritis. Ann Rheum Dis. 2018;77(9):1251-60.

10. Tierney M, Fraser A, Kennedy N. Physical activity in rheumatoid arthritis: a systematic review. J Phys Act Health. 2012;9(7):1036-48.

11. Hootman JM, Macera CA, Ham SA, Helmick CG, Sniezek JE. Physical activity levels among the general US adult population and in adults with and without arthritis. Arthritis Rheum. 2003;49(1):129-35. 
12. Demmelmaier I, Bergman P, Nordgren B, Jensen I, Opava CH. Current and maintained health-enhancing physical activity in rheumatoid arthritis: a cross-sectional study. Arthritis Care Res (Hoboken). 2013;65(7):1166-76.

13. Sokka T, Hakkinen A, Kautiainen H, Maillefert JF, Toloza S, Mork Hansen T, et al. Physical inactivity in patients with rheumatoid arthritis: data from twenty-one countries in a cross-sectional, international study. Arthritis Rheum. 2008;59(1):42-50.

14. Murphy MH, McNeilly AM, Murtagh EM. Session 1: public health nutrition: physical activity prescription for public health. Proc Nutr Soc. 2010;69(1): 178-84.

15. Nelson ME, Rejeski WJ, Blair SN, Duncan PW, Judge JO, King AC, et al. Physical activity and public health in older adults: recommendation from the American College of Sports Medicine and the American Heart Association. Med Sci Sports Exerc. 2007;39(8):1435-45.

16. Iversen MD, Frits $M$, von Heideken J, Cui J, Weinblatt M, Shadick NA Physical activity and correlates of physical activity participation over three years in adults with rheumatoid arthritis. Arthritis Care Res (Hoboken). 2017; 69(10):1535-45.

17. Demmelmaier I, Asenlof $\mathrm{P}$, Bergman $\mathrm{P}$, Nordgren B, Opava CH. Pain rather than self-reported sedentary time explains variation in perceived health and activity limitation in persons with rheumatoid arthritis: a cross sectional study in Sweden. Rheumatol Int. 2017;37(6):923-30.

18. Demmelmaier I, Dufour AB, Nordgren B, Opava CH. Trajectories of physical activity over two years in persons with rheumatoid arthritis. Arthritis Care Res (Hoboken). 2016;68(8):1069-77.

19. Arnett FC, Edworthy SM, Bloch DA, McShane DJ, Fries JF, Cooper NS, et al. The American rheumatism association 1987 revised criteria for the classification of rheumatoid arthritis. Arthritis Rheum. 1988;31(3):315-24.

20. Andersson ML, Forslind K, Hafstrom I. Comparing five year out-come in two cohorts of patients with early rheumatoid arthritis - a BARFOT study. Open Rheumatol J. 2015;9:8-15.

21. Prevoo ML, van't Hof MA, Kuper $H H$, van Leeuwen $M A$, van de Putte $L B$, van Riel PL. Modified disease activity scores that include twenty-eight-joint counts. Development and validation in a prospective longitudinal study of patients with rheumatoid arthritis. Arthritis Rheum. 1995;38(1):44-8.

22. Hurst NP, Kind P, Ruta D, Hunter M, Stubbings A. Measuring health-related quality of life in rheumatoid arthritis: validity, responsiveness and reliability of EuroQol (EQ-5D). Br J Rheumatol. 1997;36(5):551-9.

23. Ekdahl C, Eberhardt K, Andersson SI, Svensson B. Assessing disability in patients with rheumatoid arthritis. Use of a Swedish version of the Stanford health assessment questionnaire. Scand J Rheumatol. 1988;17(4):263-71.

24. Bergman S, Herrstrom P, Hogstrom K, Petersson IF, Svensson B, Jacobsson LT. Chronic musculoskeletal pain, prevalence rates, and sociodemographic associations in a Swedish population study. J Rheumatol. 2001;28(6):1369-77.

25. Haskell WL, Lee IM, Pate RR, Powell KE, Blair SN, Franklin BA, et al. Physical activity and public health: updated recommendation for adults from the American College of Sports Medicine and the American Heart Association. Med Sci Sports Exerc. 2007;39(8):1423-34.

26. Malm K, Bergman S, Bremander A, Larsson I, Andersson MLE. Discussions of lifestyle habits as an integral part of care management: a cross-sectional cohort study in patients with established rheumatoid arthritis in Sweden. Rheumatol Adv Pract. 2019;3(2):rkz039.

27. Lingfors $H$, Persson LG. All-cause mortality among young men 24-26 years after a lifestyle health dialogue in a Swedish primary care setting: a longitudinal follow-up register study. BMJ Open. 2019;9(1):e022474.

28. Sjoquist ES, Brodin N, Lampa J, Jensen I, Opava CH, group Ps. Physical activity coaching of patients with rheumatoid arthritis in everyday practice: a long-term follow-up. Musculoskeletal Care. 2011;9(2):75-85.

29. Knittle K, De Gucht V, Maes S. Lifestyle- and behaviour-change interventions in musculoskeletal conditions. Best Pract Res Clin Rheumatol. 2012;26(3): 293-304.

30. Sandberg ME, Bengtsson C, Kallberg H, Wesley A, Klareskog L, Alfredsson L, et al. Overweight decreases the chance of achieving good response and low disease activity in early rheumatoid arthritis. Ann Rheum Dis. 2014; 73(11):2029-33.

31. Sandberg ME, Wedren S, Klareskog L, Lundberg IE, Opava CH, Alfredsson L, et al. Patients with regular physical activity before onset of rheumatoid arthritis present with milder disease. Ann Rheum Dis. 2014;73(8):1541-4.

32. Sparks JA, Iversen MD, Yu Z, Triedman NA, Prado MG, Miller Kroouze R, et al. Disclosure of personalized rheumatoid arthritis risk using genetics, biomarkers, and lifestyle factors to motivate health behavior improvements: a randomized controlled trial. Arthritis Care Res (Hoboken). 2018;70(6):82333.

33. Iversen MD, Fossel AH, Ayers K, Palmsten A, Wang HW, Daltroy LH. Predictors of exercise behavior in patients with rheumatoid arthritis 6 months following a visit with their rheumatologist. Phys Ther. 2004;84(8): 706-16.

34. Malm K, Bremander A, Arvidsson B, Andersson ML, Bergman S, Larsson I. The influence of lifestyle habits on quality of life in patients with established rheumatoid arthritis-a constant balancing between ideality and reality. Int J Qual Stud Health Well-being. 2016;11:30534.

35. Gossec L, Berenbaum F, Chauvin P, Hudry C, Cukierman G, de Chalus T, et al. Development and application of a questionnaire to assess patient beliefs in rheumatoid arthritis and axial spondyloarthritis. Clin Rheumatol. 2018;37(10):2649-57.

36. Quinn T, Bs MF, von Heideken J, lannaccone C, Shadick NA, Weinblatt M, et al. Validity of the Nurses' health study physical activity questionnaire in estimating physical activity in adults with rheumatoid arthritis. BMC Musculoskelet Disord. 2017;18(1):234.

37. Loof $\mathrm{H}$, Demmelmaier I, Henriksson EW, Lindblad S, Nordgren B, Opava $\mathrm{CH}_{t}$ et al. Fear-avoidance beliefs about physical activity in adults with rheumatoid arthritis. Scand J Rheumatol. 2015;44(2):93-9.

38. Chan CB, Ryan DA. Assessing the effects of weather conditions on physical activity participation using objective measures. Int J Environ Res Public Health. 2009;6(10):2639-54.

39. Kuettel D, Primdahl J, Weber U, Terslev L, Østergaard M, Petersen R, et al. Pain and self-reported swollen joints are main drivers of patient-reported flares in rheumatoid arthritis. Results from a 12-months' observational study. J Rheumatol. 20190nline ahead of print. https://doi.org/10.3899/jrheum. 190760.

\section{Publisher's Note}

Springer Nature remains neutral with regard to jurisdictional claims in published maps and institutional affiliations.

\section{Ready to submit your research? Choose BMC and benefit from:}

- fast, convenient online submission

- thorough peer review by experienced researchers in your field

- rapid publication on acceptance

- support for research data, including large and complex data types

- gold Open Access which fosters wider collaboration and increased citations

- maximum visibility for your research: over $100 \mathrm{M}$ website views per year

At $\mathrm{BMC}$, research is always in progress.

Learn more biomedcentral.com/submissions 